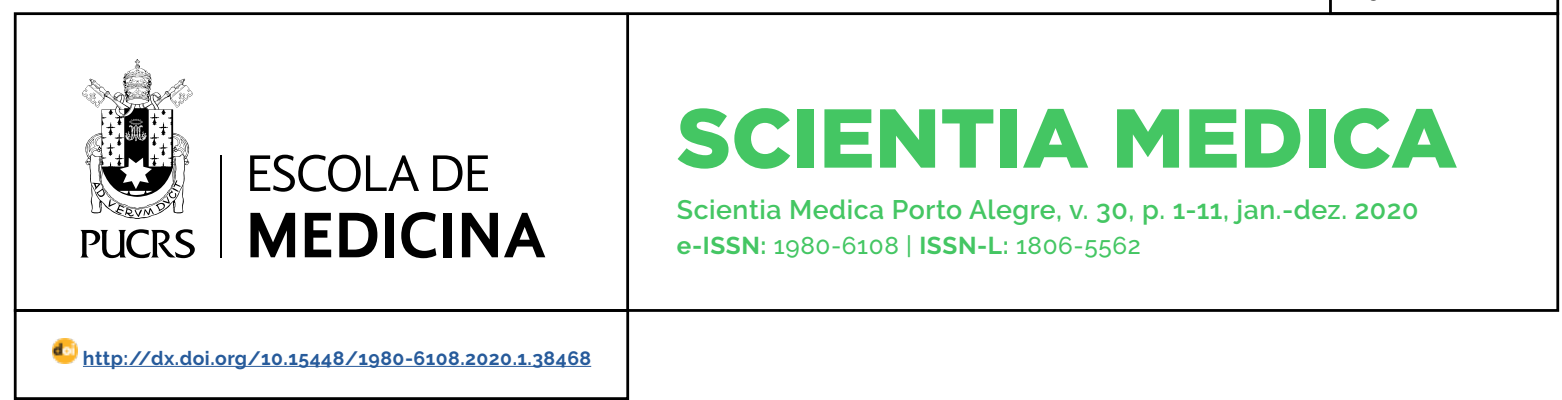

\title{
COVID-19: CUIDADOS DE ENFERMAGEM EM UNIDADE DE TERAPIA INTENSIVA
}

\author{
COVID-19 NURSING CARE IN AN INTENSIVE CARE UNIT
}

\section{Evelize Maciel de Moraes $^{1}$ \\ orcid.org/0000-0001-7874397X evelizemoraes@gmail.com}

\section{Larita Helena Albieri de Almeida ${ }^{2}$}

orcid.org/0000-0002-8078-5885 laritaalbieri@hotmail.com

\section{Elizane Giordani ${ }^{3}$}

orcid.org/0000-0002-6213-443X elizane.giordani@edu.pucrs.br

Recebido em: 13 jun. 2020 Aprovado em: 17 jun. 2020 Publicado em: 24 jul. 2020

\section{(c) (1)}

Artigo está licenciado sob forma de uma licença Creative Commons Atribuição 4.0 Internacional.
Resumo: A doença causada pelo novo coronavirus (COVID-19), foi identificada em dezembro de 2019, na China. Por ter uma disseminação extremamente rápida, de pessoa por pessoa, em janeiro de 2020 foi declarada uma urgência em saúde pública internacional e, em março, a COVID-19 foi declarada como uma pandemia. Os profissionais de saúde têm grande probabilidade de contrair ou transmitir essa doença, decorrente de sua alta exposição ao vírus. Com essa preocupação, o presente estudo fez uma revisão bibliográfica para descrever as rotinas e protocolos relacionados às melhores práticas para assistência de enfermagem aos pacientes com a COVID-19. No momento crítico como esse, cabe ao enfermeiro montar estratégias para qualificar a assistência e, ao mesmo tempo, promover a segurança dos profissionais que atuam diretamente no cuidado aos pacientes com a COVID-19.

Descritores: SARS-CoV-2; tratamento; pandemia.

Abstract: The disease caused by the new coronavirus (COVID-19) was identified in December 2019, in China. By an extremely rapid dissemination of one person per person, in January 2020, COVID-19 was declared an international public health emergency, and, in March, it was declared as a pandemic. Health professionals are very likely to contract or transmit this disease, due to their high exposure to the virus. With this concern, the present study makes a bibliographic review to describe the routines and protocols related to the best nursing care practices for patients with a COVID-19. In the critical moment like this, the nurse is the responsible to develop strategies to qualify assistance and, at the same time, promote the safety of professionals who work directly in the patients care with a COVID-19.

Keywords: SARS-CoV-2, treatment; pandemic

Abreviaturas: COVID-19, Coronavirus Disease 2019; EPI, Equipamento de proteção individual.

\section{INTRODUÇÃO}

Na cidade de Wuhan, província de Hubei da China, em dezembro de 2019, foi identificado diversos casos de pneumonia por causa desconhecida. A partir da análise do material genético foi identificado o novo coronavírus, denominado SARS-CoV-2 (Severe Acute Respiratory Syndrome Coronavirus 2). Este vírus pertence à familia Coronaviridae, os quais causam uma variedade de doenças no homem e em animais, especialmente no trato respiratório. A infecção pelo SARS-CoV-2 causas a doença denominada COVID-19 (Coronavirus Disease 2019) [1, 2].

A disseminação do COVID-19 é extremamente rápida, de pessoa por pessoa. A transmissão ocorre por contato direto (por meio das mãos), 
indireto (objetos ou superfícies contaminadas) com pessoas infectadas, aéreo (por gotículas respiratórias: fala, tosse, espirro) ou por procedimentos que geram aerossóis (intubação traqueal, aspiração de vias aéreas [3].

No dia 30 de janeiro de 2020 , em razão da disseminação da COVID-19, a Organização Mundial de Saúde declarou emergência em saúde pública de importância internacional, o nivel de alerta mais importante da história atual. Nesse dia, a China tinha 7,7 mil casos confirmados e 170 óbitos e, outros 18 países apresentavam 98 casos. Em 11 de março de 2020, a COVID-19 foi declarada como uma pandemia [4]. Dados mundiais mostraram que, em 13 de junho, foram confirmados 7.626.279 casos de COVID-19, com 425.931 mortes. No Brasil, entre 26 de fevereiro e 13 de junho de 2020 , houve 850.514 casos confirmados, 41.828 mortes e 379.245 recuperados pela COVID-19. Dentre os países com mais de um milhão de habitantes, o Brasil, no período entre 07 e 13 de junho, estava na $18^{a}$ posição no coeficiente de incidência, na $12^{a}$ posição nos óbitos e era o segundo país de maior número de recuperados [5].

A maioria dos pacientes com a COVID-19 apresenta um quadro leve da doença. As manifestações podem ser desde quadros respiratórios brandos até pneumonia grave com insuficiência respiratória. Aproximadamente $15 \%$ dos pacientes com COVID-19 necessitam de atendimento hospitalar e, desses, 5\% requerem ventilação mecânica assistida devido à insuficiência respiratória. Sua gravidade e mortalidade modifica de acordo com a faixa etária, sendo maior em indivíduos com mais de 60 anos, os portadores de diabetes e doenças cardiocirculatórias, os imunodeprimidos, as gestantes de alto risco e os profissionais de saúde [2, 6, 7].

O diagnóstico da COVID-19 é realizado pela reação em cadeia da polimerase com transcrição reversa em tempo real (Reverse Transcription Polymerase Chain Reaction) ou pela determinação sorológica de anticorpos contra o coronavírus [8]. A reação em cadeia da polimerase com transcrição reversa em tempo real verifica a presença de material genético do vírus em material obtido por raspado (swab) de nasofaringe e orofaringe. Preferencialmente, a coleta deve ser feita a partir do $3^{\circ}$ dia após o início dos sintomas e até $010^{\circ}$ dia, pois ao final deste periodo a quantidade de RNA tende a diminuir. Na avaliação sorológica, a presença de anticorpos da classe lgM tende a indicar uma resposta imune recente, enquanto a detecção de anticorpos IgG indicam uma fase posterior ao contato com patógeno. Ainda não se sabe por quanto tempo os anticorpos IgM e IgG para COVID-19 permanecem no corpo. Este teste possibilita o mapeamento da população que foi exposta ao vírus, o que poderia contribuir no processo de relaxamento das medidas restritivas $[9,10]$.

Até o presente momento não há vacina e nem medicamento especifico para prevenir ou tratar a COVID-19. Os pacientes infectados devem receber cuidados de saúde para aliviar os sintomas e aqueles com maior agravamento da doença devem ser hospitalizados. No atendimento, deve-se levar em consideração os demais diagnósticos diferenciais pertinentes e o adequado manejo clínico para cada paciente [11].

A contagiosidade do vírus, a grande proporção de infectados, a inexistência de uma vacina e de terapia medicamentosa comprovada para essa doença, a insuficiência de testes e as medidas de isolamento social que determinaram que só os serviços essenciais fossem mantidos, intensificaram as tarefas dos profissionais de saúde [12].

Reconhece-se que os profissionais de saúde têm significativa probabilidade de contrair ou transmitir doenças decorrente a sua exposição a virus e bactérias. Com a pandemia, o Ministério da Saúde antecipou a imunização contra a influenza sazonal para todos os profissionais e a comunidade de risco, tendo como objetivo prevenir quadros graves de doenças respiratórias pela gripe e, com isso, auxiliando as equipes e ao sistema de saúde a concentrarem-se no combate à COVID-19 [2].

A presente revisão descreve, de forma resumida, as rotinas e protocolos relacionadas às melhores práticas descritas para assistência de enfermagem aos pacientes com a COVID-19, elaborados por entidades públicas governamentais 
nacionais e mundiais e associações e conselhos de medicina e de enfermagem brasileiros. Artigos considerados relevantes foram identificados a partir do banco de dados da PubMed, da Organização Mundial de Saúde e da BIREME (Centro Latino-Americano e do Caribe de Informação em Ciências da Saúde) no periodo entre dezembro de 2019 e junho de 2020, utilizando os termos "COVID-19", SARS-CoV-2", "Cuidados de enfermagem" e "Nursing care", cruzando-os com os operadores "AND", "OR" e "NOT". A seleção desses artigos foi por análise de conveniência pelos autores.

\section{MEDIDAS GERAIS DE CUIDADOS}

Desde o início da disseminação da COVID-19, uma série de medidas de proteção têm sido divulgadas e ensinadas à população como lavar as mãos frequentemente com água e sabão ou álcool em gel a 70\%, adotar medidas de etiqueta respiratória (cobrir a boca com o antebraço ou utilizar um lenço descartável quando tossir ou espirrar e lavar as mãos), manter um distanciamento social, no mínimo, de um metro, evitar aglomerações e utilizar máscaras faciais em casos de contaminações ou sintomas gripais, assim como, pelos profissionais de saúde [5, 13]. Outro cuidado recomendado é o autoisolamento das pessoas com mais de 60 anos e daquelas com doenças pré-existente $[4,6]$.

\section{PRÁTICAS ADMINISTRATIVAS}

Em situações de pandemia, como na COVID-19, é de extrema necessidade que as instituições montem um comitê de crise, com a finalidade de alinhar as demandas para o atendimento da população. Esse comitê deve ser formado pela direção técnica, pelos responsáveis do controle de infecção hospitalar, pelo serviço de segurança e medicina do trabalho, pelos gestores das áreas assistenciais e de apoio e pela gestão administrativa de qualidade [3].

Um dos principais problemas relacionados à assistência ao paciente com COVID-19 é a garantia no fornecimento diuturnamente de equipamentos de proteção individual (EPI) a todos os profissionais assistencialistas. Assim, é essencial para a segurança dos colaboradores, a manutenção de um estoque mínimo necessário de EPI [3, 14].

Os profissionais que atuam por longas horas e próximos a pacientes vulneráveis em ambientes de saúde, é de suma importância estarem capacitados e equipados com EPI, não somente para impedir a transmissão desse agente para outras pessoas, mas também para diminuir ao máximo o risco de contrair a doença. No atual momento, o cenário não é diferente. Há uma tendência em aumentar a contaminação pela demanda apresentada na saúde, necessitando abordagem e controle ainda mais rigorosos [15].

Quanto ao dimensionamento de pessoal em uma unidade de terapia intensiva é importante manter um quantitativo mínimo dos diferentes níveis de formação para a cobertura assistencial nas instituições de saúde. É importante os gestores estarem atentos que nessa pandemia é crescente ao número de profissionais que podem necessitar de licença de saúde por terem sido contaminados [1]. Por sua vez, os profissionais de enfermagem com mais de 60 anos, as gestantes ou lactantes e as portadores de doenças do grupo de risco deverão ser protegidos, através do afastamento do serviço ou realocação para outros setores [3].

Nos casos onde o profissional de saúde assintomático tiver contato domiciliar com uma pessoa diagnosticada com COVID-19, o mesmo deverá ficar afastado das suas funções por 14 dias e realizar o teste rápido no final do afastamento. Já os casos de profissionais com sintomas gripais, esse deve ser testado para COVID-19 e somente após o resultado poderá retornar ao trabalho, respeitando-se as diretrizes de cada instituição [4].

\section{COMPORTAMENTO DOS PROFISSIONAIS INTENSIVISTAS}

Para 0 atendimento dos pacientes com COVID-19 em unidades de tratamento intensivo, os profissionais devem levar em consideração o manejo adequado da rotina diária, contribuindo com a segurança nas práticas assitenciais. Do mesmo modo, todos os profissionais devem ser capacitados para a prevenção da transmissão de agentes infecciosos e para o uso adequado dos EPI. Os profissionais envolvidos devem respeitar 
as normas e rotinas de cada instituição, visando a segurança da equipe de trabalho e do paciente [12].

Dentre tantas medidas de controle e prevenção de infecções, especialmente na COVID-19, a que mais se destaca é a higienização das mãos comágua e sabonete liquido (por 40 a 60 segundos) ou com preparação alcoólica a 70\% (por 20 a 30 segundos) [5, 16]. É um procedimento simples e muito eficaz que impede a transmissão de uma pessoa para outra.

Do mesmo modo, os profissionais devem manter as unhas curtas e limpas, a barba feita ou aparada, utilizar sapatos fechados, confortáveis e com solado de borracha para evitar escorregões e barulho [14]. Para a jornada de trabalho, os preparativos iniciam com a retirada de adornos (anéis, alianças, correntes, brincos etc.), a manutenção dos cabelos presos e a remoção de utensílios de uso pessoal como celulares, tesouras, canetas, dentre outros [2, 14].

A utilização dos EPI é indispensável para a prevenção. Preconiza-se que as vestimentas a serem utilizadas sejam fornecidas pelo hospital: macacão, capote ou avental impermeável (gramatura mínima de $50 \mathrm{~g} / \mathrm{m}^{2}$ ) de manga longa, com punho de malha ou elástico e abertura posterior. Essa vestimenta deve ser amarrada no pescoço e na cintura e deve ser verificado se está bem fechado nas costas. Todo capote ou avental que apresentar sujidade deve ser removido e descartado após a realização do procedimento, antes de sair do quarto do paciente ou da área de assistência. Após a remoção do capote, deve-se proceder imediatamente a higienização das mãos para evitar a autotransmissão ou a transmissão do vírus para outros profissionais, aos pacientes e ao ambiente. O descarte de roupas sujas utilizadas pelos profissionais deve ser realizado com cuidado em recipiente apropriado [17].

Para o processo de lavagem das roupas, tanto as utilizadas pela equipe de saúde quanto as que tiveram contato com pacientes com COVID-19, o processo é o mesmo utilizado para as roupas provenientes de quaisquer outros pacientes [11].

A máscara facial indicada na assistência para a COVID-19 é a FFP3 ou, se essa não estiver disponivel, a FFP2 ou N95. Deve-se vestir gorro e óculos de proteção ou a máscara protetora de face (face shield) quando houver risco de exposição do profissional a respingos de sangue, secreções corporais e excreções. Devem ser de uso exclusivo para cada profissional responsável pela assistência, sendo necessária a higienização correta após o uso $[2,15,17]$.

\section{CUIDADOS COM O CUIDADOR}

Para esses profissionais de saúde que atuam na linha de frente no cuidado na assistência ao paciente em condição crítica devem seguir cuidados para a saúde mental [18]. Fazer descansos entre os turnos de trabalhos, se possivel durante o expediente, alimentar-se com dieta saudável e hidratação, manter contato com familiares sempre que possivel, mesmo sendo virtual. Os coordenadores das unidades devem estar disponiveis para oferecer um apoio social e manter contato livre com a equipe de psicologia [14, 19].

Para minimizar o estresse e o controle emocional, deve-se assegurar uma equipe suficiente para cada turno de trabalho, realizando rodizio para as áreas com menor exposição e os funcionários menos experientes com os mais experientes. A boa relação entre colegas auxilia na redução do estresse e promove um ambiente mais seguro [19].

Ao retornar para sua casa o profissional de saúde deve estar ciente sobre a realização de algumas ações recomendadas para o seu cuidado pessoal e das pessoas com quem reside, como: lavar as mãos vigorosamente, higienizar objetos pessoais (celular, chaves, bolsas, etc.), retirar roupas e sapatos e os acondicionar em área de ventilação natural e tomar banho [5].

\section{COLETA DE MATERIAIS DA COVID-19}

Para a investigação laboratorial de infecção respiratória da COVID-19 é recomendada a coleta de material da nasofaringe, da orofaringe ou de secreção do trato respiratório inferior. Antes de realizar o procedimento, procura-se organizar o ambiente, usar EPI adequadamente, conversar com o paciente, explicando o passo a passo do procedimento, avaliar se o mesmo apresenta desvio de septo nasal, usar técnica asséptica e identificar o material coletado [8, 10]. 
O material é obtido por raspado de nasofaringe e orofaringe por um profissional de enfermagem ou médico. O profissional capacitado deverá introduzir o swab pela narina até a nasofaringe (Figura 1A), realizando movimentos rotatórios para captar células da nasofaringe e absorver secreção respiratória. Esse procedimento é realizado em ambas as narinas. Um terceiro swab será utilizado na coleta de secreção respiratória da parte posterior da orofaringe, evitando contato com a língua para minimizar a contaminação (Figura 1B) [20].

A

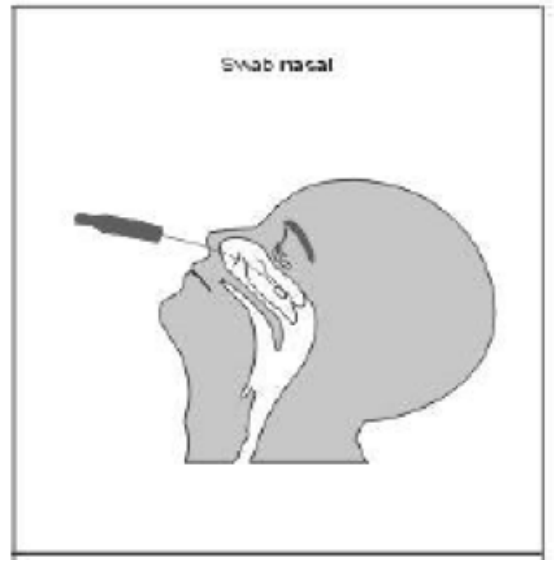

B

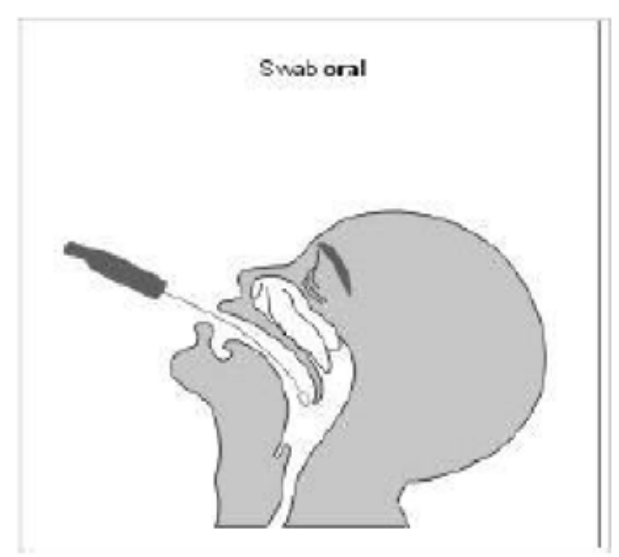

Figura 1 - Swab de coleta de material para COVID-19. A) nasofaringe. B) orofaringe

Fonte: LACEN/CEVS/SES-RS [20]

Para a coleta do trato respiratório inferior, o profissional deverá realizar lavado broncoalveolar ou aspirado traqueal. Coleta-se 2 a $3 \mathrm{ml}$ desse material em um frasco estéril. Nas situações onde a secreção é espessa, recomenda-se ins- tilar gotas de solução fisiológica estéril (cloreto de sódio a 0,9\%), a fim de promover a fluidez do muco, facilitando a aspiração. Preconiza-se o uso de sistema fechado de aspiração, com o frasco acoplado à ponta do dispositivo, minimizando a liberação de aerossóis no ambiente [10].

As amostras devem ser mantidas em temperaturas de $4^{\circ}$ a $8^{\circ} \mathrm{C}$ e devem ser enviadas ao laboratório de referência para serem analisadas entre 24 e 72 horas após a coleta. Se as amostras não forem analisadas dentro desse período, recomenda-se o congelamento a $-70^{\circ} \mathrm{C}$, em gelo seco ou nitrogênio líquido [10].

\section{ROTINAS BÁSICAS EM UNIDADE DE TERAPIA INTENSIVA}

A prevenção da disseminação da COVID-19 tem papel importante em pacientes críticos. $O$ conhecimento da doença e a necessidade de manejo com os pacientes em uso de tecnologias requer um amplo conhecimento e domínio dos princípios que regem este cuidado e tornam, a equipe de enfermagem, um componente fundamental para o desfecho desses pacientes.

$\mathrm{O}$ isolamento deve ser realizado, preferencialmente, em um quarto privativo, com portas fechadas e com pressão negativa ou bem ventilados [1, 19]. Quando não houver a possibilidade de um quarto privativo, é fundamental que seja mantida uma distância mínima de um metro entre os leitos e proceder com isolamento de coorte, ou seja, separando nesta mesma área todos os pacientes com a COVID-19. Essa área deve ser bem sinalizada, especialmente quanto às medidas de precaução a serem adotadas: padrão, gotículas e contato ou aerossóis. A circulação de funcionários que não trabalham com esses pacientes deve ser evitada e as visitas limitadas [1, 2].

Ao entrar no box do paciente, o profissional deverá higienizar as mãos e usar luvas. O uso de luvas não elimina a higienização correta das mãos, sempre antes e após a realização de procedimentos ou do atendimento $[2,16]$.

O paciente crítico portador da COVID-19 necessita de constante e rigorosa vigilância dos seus sinais vitais. Dentro desse contexto, torna-se im- 
prescindivel que a equipe assistencial da unidade de terapia intensiva seja capaz de reconhecer e identificar precocemente todas as alterações hemodinâmicas, através da monitorização rigorosa e atenta. O enfermeiro intensivista deve estar apto a analisar esses dados, somados à história do paciente, à avaliação dos sistemas, o exame físico, além de resultados laboratoriais e de imagem. O enfermeiro também é o responsável por aplicar escalas avaliativas (Glasgow, Braden, dentre outras), para avaliar a integridade da pele, principalmente nas regiões submetidas a pressão, utilizar curativos profiláticos para proteção dessas áreas. Se o paciente apresentar lesões cutâneas, procurar selecionar a cobertura apropriada, priorizando as que promovem longa duração e pouca aderência à pele. Para os cuidados de sondas, drenos, cateteres e tubos traqueais indica-se a aplicação de película protetora epidérmica para, com isso, evitar o aparecimento de lesões e manter esses dispositivos bem fixos, evitando-se a tração. É possivel construir através dos dados clínicos, uma rotina de cuidados instrumentados pela prescrição e norteada pelos diagnósticos de enfermagem [21- 24].

\section{CUIDADOS NA TERAPIA RESPIRATÓRIA}

O tratamento para pacientes com a COVID-19 dependerá da gravidade. Nos casos de pacientes críticos com dificuldade respiratória, hipoxemia e uma $\mathrm{SpO}_{2}$ menor que 93\%, deve-se imediatamente ofertar oxigenoterapia por cateter ou máscara nasal adequada às narinas, para melhor adaptação e conforto. O enfermeiro, além de supervisionar a instalação de oxigênio com o material adequado, orienta o paciente a manter a boca fechada sempre que possivel. Não se recomenda a máscara tipo Venturi, a tenda e o uso do cateter de alto fluxo pelo risco de maior quantidade do vírus flutuar em gotículas de aerossol no ambiente. $O$ controle rigoroso dos sinais vitais, especialmente da saturação de oxigênio, pode interferir positivamente no desfecho do tratamento [22, 25].

Os casos mais graves podem evoluir para insuficiência respiratória. Indica-se a intubação traqueal para os pacientes que apresentam necessidade de oxigênio nasal acima de 5 litros/minuto, para manter $\mathrm{SpO}_{2}>93 \%$ e/ou apresentarem frequência respiratória acima de 28 incursões respiratórias por minuto ou retenção de $\mathrm{CO}_{2}\left(\mathrm{PaCO}_{2}>50 \mathrm{mmHg}\right.$ e/ou $\mathrm{pH}<7,25)$. Esse procedimento deve ser realizado, preferentemente, por uma equipe mínima e experiente, seguindo a técnica da sequência rápida de intubação [25]. A lidocaina tem sido utilizada como pré-medicação, pois possui propriedade de abolir os reflexos laríngeos e de potencializar o efeito anestésico de outras drogas [19, 25]. Durante a intubação alguns materiais são usados para diminuir a exposição aos aerossóis. A utilização do capnógrafo é muito importante, porque auxilia na confirmação da intubação traqueal, evitando maior exposição à contaminação por conta da ausculta. Após a intubação, conecta-se o tubo traqueal a um circuito fechado. Evita-se utilizar ventilação manual e a aspiração do sistema deve acontecer somente com o mesmo fechado. Para as trocas de filtros ou do sistema fechado do ventilador, utiliza-se a pinça forte para clampear o tubo traqueal [1, 19, 25].

Compete ao enfermeiro a montagem dos circuitos, do filtro respiratório (HMEF, Heat and Moisture Exchanger), do sistema de umidificação, da testagem e da instalação da ventilação mecânica invasiva, com supervisão da equipe médica, assim como o sistema de aspiração à vácuo, as entradas de oxigênio e de ar comprimido, com seus respectivos adaptadores e extensores $[1,19,22]$. É fundamental que todos os equipamentos estejam testados e prontos para serem utilizados. O registro adequado das variações dos parâmetros do ventilador mecânico é de responsabilidade da equipe de enfermagem treinada.

\section{CUIDADOS COM O POSICIONAMENTO DO PACIENTE}

Uma das abordagens utilizada para melhorar a hipoxemia nos pacientes com sindrome do desconforto respiratório agudo é a posição prona (decúbito ventral). Apesar ser considerada um modo eficaz de melhorar a oxigenação, os mecanismos fisiológicos que levam à melhora da função respiratória ainda não estão completamente esclarecidos. Acredita-se que a posição 
prona remova a contrapressão exercida nos pulmões pela pressão abdominal transmitida pelo diafragma e pelo coração e, também, melhora a pressão negativa nos pulmões, abrindo os alvéolos e melhorando a relação ventilação/perfusão. Está indicada nos pacientes com sindrome do desconforto respiratório agudo grave (relação pressão parcial arterial de oxigênio/fração inspirada de oxigênio < 150) [11, 26, 27].

Para realizar a preparação completa desse procedimento, inicia-se a abordagem desse assunto com a família do paciente, explicando-os detalhadamente e os seus beneficios. Após, procura-se avaliar se a condição hemodinâmica do paciente se encontra estável suficientemente para tolerar o manuseio; verificar o peso do paciente e o tamanho da cama e preparar a equipe necessária. Se o paciente estiver sendo alimentado, procura-se pausar o consumo de alimentos por, no mínimo, uma hora antes do procedimento. Do mesmo modo, se houver curativos na face ventral do corpo para serem trocados, realizá-los antes. Estar atento aos curativos preventivos de proeminências ósseas, como os ombros, quadris, joelhos e pés. Manter os olhos umidificados e, se necessário, utilizar uma vedação para mantê-los fechados. Avaliar a cavidade oral: se a lingua do paciente estiver saliente, usar um bloco de mordida e assegurar que o tubo e demais drenos estejam bem fixados. Certificar-se que os materiais de urgência estejam montados e acessiveis no caso de extubação acidental [21, 26, 27].

Para a posição prona é necessária uma equipe de cinco profissionais: Dois profissionais de cada lado da cama, localizados entre os joelhos e o quadril, outros dois na altura do tórax e o último na cabeça. Quem dará os comandos é o responsável da via área. Mantem-se o paciente conectado no respirador em sistema fechado, realiza-se a remoção dos eletrodos (monitor de eletrocardiograma e sensor de saturação). Remove-se a camisola, mantendo o paciente coberto com um lençol móvel e outro lençol por cima. Realizar o enrolamento dos lençóis, de cima e de baixo, nos dois lados. Estes lençóis enrolados são os que movimentarão o paciente.
Na contagem do profissional da cabeceira, primeiramente, realiza-se o movimento em bloco, ao lateral da cama, deixando-o em $90^{\circ}$ graus. $\mathrm{Na}$ nova contagem, realiza-se a posição prona. Em seguida, os membros da equipe organizam os lençóis, colocam o paciente em posicionamento confortável e monitoram o paciente. Geralmente, há uma desestabilização do paciente nesse procedimento, levando cerca de 10 minutos para voltar a se estabilizar. O controle do tratamento do decúbito ventral é iniciado pela coleta de gasometria, trinta minutos após. Recomenda-se a posição prona por 12 a 24 horas [11, 26, 27].

\section{MANIPULAÇÃO DE MEDICAMENTOS}

Mesmo que até o presente momento não conste medicação para combater a COVID-19, muitos fármacos são administrados para as complicações dessa doença. É muito frequente a utilização de drogas sedativas, analgésicos e vasoativas pela sua gravidade. Por isso, é necessário ter acesso venoso de bom calibre e ter atenção quanto ao extravasamento da droga. Sempre que possivel, dar a preferência para um cateter central. A equipe de enfermagem é responsável pela manutenção do acesso venoso, periférico ou central, e pela preparação e administração de medicamentos, independentemente do local de assistência [23, 24].

Ao preparar a medicação, o profissional deve estar atento aos cuidados básicos de limpeza do local onde irá prepará-la, após higienizar as mãos e utilizando os principios ("cinco certos") para uma administração segura do fármaco: o medicamento, a dose, a via, o horário e o paciente. Essas etapas funcionam como uma forma de melhorar a qualidade no atendimento. Não menos importantes são a checagem, o registro e o controle de assepsia antes e após cada procedimento e/ou medicação aplicada [23].

Os prontuários, normalmente são compostos por papel, pranchetas de plástico e grampos em aço inoxidável e são manuseados por diversos integrantes da equipe assistencial. Observou-se que a estabilidade do COVID-19 nas superficies depende do tipo de material onde ele foi depositado. Em papelão, nenhum COVID-19 viável foi 
encontrado após 24 horas e em aço inoxidável e plástico, após 72 horas [28]. Em razão disso, recomenda-se que o profissional circulante, que não tenha contato com o paciente acometido por COVID-19, realize os registros. Na ausência desse profissional exclusivo para exercer essa função, deve-se retirar a paramentação e higienizar as mãos antes de ter contato com o prontuário. Essa recomendação também se aplica no manuseio de computadores e dispositivos eletrônicos nas instituições que disponibilizam de prontuário eletrônico. Cabe enfatizar que não é recomendado que o prontuário entre em contato com o paciente e/ou a maca de transporte durante o transporte intra-hospitalar [2, 28].

\section{PRECAUÇÕES COM HIGIENIZAÇÃO E DESINFECÇÃO}

Em relação à limpeza e à desinfecção de superfícies, não há diferenças instituidas à COVID-19. Devem-se manter os cuidados de precauções com o uso de EPI e aos adotados a todos os tipos de isolamentos, mantendo a técnica correta na higienização, tanto das superfícies metálicas, das paredes e do chão. Os produtos para limpeza incluem aqueles à base de cloro, álcoois, alguns fenóis, iodóforos e o quaternário de amônio. Todos os equipamentos utilizados na assistência ao paciente (bomba de seringa, ventilador mecânico, monitor cardiaco, estetoscópio, esfigmomanômetro, termômetro, bancadas, bordas das camas e macas etc.) deverão ser limpos a cada término da jornada de trabalho, ainda com os profissionais usando os EPI e evitando o contato com os materiais infectados [2, 11, 17].

No isolamento, sempre que possivel, equipamentos relacionados à assistência de aferição de sinais vitais, como estetoscópio, esfigmomanômetro e termômetro, devem ser de uso exclusivo para cada paciente. O equipamento deve ser limpo e desinfectado, antes de ser utilizado em outro paciente, quando da necessidade de compartilhamento [2, 11, 17].

O enfermeiro deve estar atento na utilização dos produtos adequados e ao uso de EPI nos processos de limpeza e desinfecção dos ambientes.
Os profissionais da higienização devem receber os treinamentos necessários para manipular os produtos e como utilizá-los, mantendo-os atento aos conceitos de áreas críticas, semicríticas e não crítica, assim como a limpeza concorrente, a limpeza imediata e a limpeza terminal $[2,11,17]$.

\section{PREPARO PARA A ALTA}

Para garantir uma transição segura no cuidado é realizado um planejamento de ações deixando esse paciente preparado para sua transferência do setor, do serviço ou direto para sua casa (alta hospitalar).

O enfermeiro enfrenta um grande desafio para preparar o paciente e familiar, transferindo a continuidade do cuidado realizado, garantindo entendimento familiar e do paciente sobre uso correto das medicações e alimentação. Para esse planejamento terá que antecipar o cuidado, a educação do autogerenciamento, a comunicação e garantir o acompanhamento ambulatorial, apoio social e necessidades específicas, bem como, as orientações de higiene, conforto e restrições de visitas em sua residência.

Caso ocorrer o falecimento do paciente, outras ações deverão ser tomadas. Nesse momento da pandemia, o aspecto emocional da equipe está muito abalado. O enfermeiro se depara com novo desafio na parte emotiva e na segurança de sua equipe. Além disso, mesmo com seu próprio medo de contaminação, o enfermeiro precisa garantir assistência familiar que está em luto [18].

O profissional da equipe mais habilitado e preparado emocionalmente irá proceder ao preparo do corpo com os materiais necessários e encaminhar à câmara fria no necrotério, promovendo o descarte correto de todo o material utilizado por esse paciente [2]. Desse modo, o enfermeiro organiza o recebimento dos familiares para a notícia do óbito e informa a equipe de psicologia e/ou assistência social para realizar o atendimento multiprofissional necessário. É recomendado, no máximo, a participação de dois familiares nesse momento difícil, para que um apoie o outro, desde que nenhum deles tenha os sintomas da COVID-19 [29].

Após a alta ou óbito do paciente com COVID-19, seu prontuário deve ser identificado cui- 
dadosamente e deve ser acondicionado em uma embalagem de saco plástico transparente, em local indicado pela instituição e mantido neste por um periodo de 72 horas após o último uso. A inserção e retirada do prontuário do saco plástico deve ser realizado por profissional após ter as mãos devidamente higienizadas e em uso de EPI apropriados (máscara cirúrgica) e realizar a higiene de mãos logo após o manuseio [15, 27].

\section{CONCLUSÃO}

Esses conceitos são básicos e fundamentais para assistência e a segurança do paciente e ao próprio profissional, em um momento com uma doença preocupante sobre a COVID-19. O enfermeiro deverá ter o conhecimento sobre as medidas de prevenção e segurança dos profissionais que atuam nos cuidados, às recomendações de prevenção da disseminação da doença, assim como as complicações relacionadas para que possa utilizar estratégias para minimizar ou prevenir os efeitos adversos desta prática, traçando um plano de cuidados de acordo com a necessidade de cada paciente. As principais complicações relacionadas a COVID-19 são as das vias aéreas, pulmonares, extrapulmonares e infecciosas. É de suma importância que sejam instaladas medidas de suporte ventilatório adequadas a cada paciente e que a equipe multidisciplinar esteja preparada para atuar de forma coesa, possibilitando a instauração de cuidados e técnicas avançadas e pertinentes a cada caso. Para isso, o treinamento da equipe de saúde, e especificamente da equipe de enfermagem, é de fundamental importância, pois assim serão prestados cuidados humanizados e de qualidade aos pacientes com a COVID-19 em unidade de terapia intensiva.

\section{NOTAS}

\section{Apoio financeiro}

Este estudo não recebeu apoio financeiro de fontes externas.

\section{Declaração de conflito de interesses}

Os autores declaram não haver conflitos de interesses relevantes ao conteúdo deste estudo.

\section{Contribuições dos autores}

Todos os autores fizeram contribuições substanciais para concepção, ou delineamento, ou aquisição, ou análise ou interpretação de dados; e redação do trabalho ou revisão crítica; e aprovação final da versão para publicação.

\section{Disponibilidade dos dados e responsabilidade pelos resultados}

Todos os autores declaram ter tido total acesso aos dados obtidos e assumem completa responsabilidade pela integridade destes resultados.

\section{REFERÊNCIAS}

1. Ribeiro MLB. Conselho Federal de Medicina. Parecer CFM n ${ }^{\circ} 4 / 2020$. Tratamento de pacientes portadores de COVID-19 com cloroquina e hidroxicloroquina. ICitado 2020 junho 08] 2020. Disponivel em: http://www. saude.mppr.mp.br/arquivos/File/Corona/CFM/6.pdf.

2. Brasil. Agência Nacional de Vigilância Sanitária (ANVISA) Gerência Geral de Tecnologia em Serviços de Saúde. Gerência de Vigilância e Monitoramento em Serviços de Saúde. Nota Técnica GVIMS/GGTES/ANVISA N04/2020 - Orientações para serviços de saúde: medidas de prevenção e controle que devem ser adotadas durante a assistência aos casos suspeitos ou confirmados de infecção pelo novo Coronavirus (SARS-CoV-2). ICitado 2020 jun 13]. 2020. 92p. Disponivel em: portal.anvisa.gov.br/documents/33852/271858/Nota+Técnica+n+04-2020+GVIMS-GGTES-ANVISA/ab598660-3de4-4f14-8e6f-b9341c196b28

3. Associação Brasileira de Enfermeiros Obstetras (ABENFO). Sociedade Brasileira de Enfermeiros Pediátricas. COVID-19. Nota técnica referente aos cuidados da equipe de enfermagem obstétrica, neonatal e pediátrica diante de caso suspeito ou confirmado. ICitado 2020 junho 08]. 2020. Disponivel em: https://sobep. org.br/wp-content/uploads/2020/04/Nota-Tecnica-COVID-19-Enfermagem-Obstã (trica_Neo_Ped.pdf

4. Brasil. Ministério da Saúde. Secretaria de Vigilância em Saúde - Boletim Epidemiológico Nº6 - Doença pelo Coronavirus 2019. Centro de Operações de Emergências em Saúde Pública - COVID-19. ICitado 2020 junho 08]. 2020. Disponivel em: https://portalarquivos. saude.gov.br/images/pdf/2020/April/03/BE6-Boletim-Especial-do-COE.pdf. Disponivel em: https://portalarquivos.saude.gov.br/images/pdf/2020/April/03/ BE6-Boletim-Especial-do-COE.pdf

5. Brasil. Ministério da Saúde. Secretaria de Vigilância em Saúde. Boletim Epidemiológico $N^{\circ} 18$ - Doença pelo Coronavirus 2019. Centro de Operações de Emergências em Saúde Pública | COVID-19. ICitado 2020 junho 14l. 2020. Disponivel em: http://saude.gov.br/ images/pdf/2020/June/18/Boletim-epidemiologico-COVID-2.pdf. 
6. McMichael TM, Currie DW, Clark S, Pogosjans S, Kay M, Schwartz NG, et al. Epidemiology of covid-19 in a long-term care facility in King County, Washington. N Engl J Med. 2020:382(21):2008-11. https://doi. org/10.1056/nejmoa2005412

7. Bornstein SR, Rubino F, Khunti K, Mingrone G, Hopkins $D$, Birkenfeld AL, et al. Practical recommendations for the management of diabetes in patients with COVID-19. Lancet Diabetes Endocrinol. 2020;8(6):546-50. https:// dx.doi.org/10.1016/S2213-8587(20)30152-2

8. Siordia JA. Epidemiology and clinical features of COVID-19: A review of current literature. J Clin Virol. 2020;127:104357. https://doi.org/10.1016/j. jcv.2020.104357

9. Brasil. Agência Nacional de Vigilância Sanitária (ANVISA). Testes para Covid-19: perguntas e respostas. [Citado 2020 Jun 06]. 2020. Disponivel em: portal.anvisa. gov.br/documents/219201/4340788/Perguntas+e+respostas+-+testes+para+Covid-19.pdf/9fe182c3-859b$-475 f$-acgf-7d2a758e48e7

10. World Health Organization. Pan American Health Organization (PAHO). Laboratory guidelines for detection and diagnosis of the novel coronavirus (2019-nCoV) infection. [Citado 2020 Jun 06]. 2020. Disponivel em: https://www.paho.org/en/documents/ laboratory-guidelines-detection-and-diagnosis-novel-coronavirus-2019-ncov-infection.

11. Brasil. Ministério da Saúde. Secretaria de Atenção Especializada à Saúde (SAES). Departamento de Atenção Hospitalar, Domiciliar e de Urgência (DAHU). Coordenação-Geral de Urgência (CGURG). Força Nacional do Sistema Único de Saúde (FN-SUS). Protocolo de tratamento do novo coronavírus (2019-nCoV). Brasília. [Citado 2020 Jun 06]. 2020. Disponivel em: https:// portalarquivos2.saude.gov.br/images/pdf/2020/fevereiro/11/protocolo-manejo-coronavirus.pdf

12. Jackson JMF Ávila AA, Algranti E, Garcia EG, Saito CA, Maeno M. A saúde do trabalhador e o enfrentamento da COVID-19. Rev. Bras. Saúde Ocup. 2020;45: e 14. http:// dx.doi.org/10.1590/2317-636gedo000120

13. Chu DK, AkLEA, Duda S, Solo K, Yaacoub S, Schünemann $\mathrm{HJ}$, et al. Physical distancing, face masks, and eye protection to prevent person-to-person transmission of SARS-CoV-2 and COVID-19: a systematic review and meta-analysis. Lancet. 2020;6736(20):1-15. https://doi. org/10.1016/S0140-6736(20)31142-9

14. Brasil. Ministério do Trabalho. Norma Regulamentadora NR 32 - Segurança e Saúde no Trabalho em Serviços de Saúde. Brasília. Diário Oficial da União. 16/11/05. [Citado 2020 Jun 04]. 2005. Disponivel em: https://enit.trabalho.gov.br/portal/images/Arquivos_ SST/SST_NR/NR-32.pdf

15. Organização Mundial da Saúde. Organização Pan-Americana da Saúde (OPAS). Orientação sobre o uso de máscaras no contexto da COVID-19. Orientação provisória. 05 de junho de 2020. [Citado 2020 Jun 06]. Disponivel em: https://iris.paho.org/bitstream/handle/10665.2/52254/OPASWBRACOVID-1920071_por. pdf? sequence $=1$ \&isAllowed $=y$
16. Oliveira AC de, De Paula AO, Souza MA de, Silva AG. Adesão à higiene de mãos entre profissionais de um serviço de pronto atendimento. Revista de Medicina. 2016:95(4):162-67. https://doi.org/10.11606/issn.1679g836.v95i4p162-167

17. Oliveira AC, Lucas TC, Iquiapaza RA. O que a pandemia da COVID-19 tem nos ensinado sobre adoção de medidas de precaução? Texto Contexto - Enferm. 2020;29:e20200106. https://doi.org/10.1590/ 1980-265X-TCE-2020-0106

18. Li Z, Ge J, Yang M, Feng J, Qiao M, Jiang R, et al. Vicarious traumatization in the general public, members, and non-members of medical teams aiding in COVID-19 control. Brain Behav Immun. 2020; So889-1591(20)30309-3. https://doi.org/10.1016/i. bbi.2020.03.007

19. Dal-Pizzol F. Associação de Medicina Intensiva Brasileira (AMIB). Recomendações da Associação de Medicina Intensiva Brasileira para a abordagem do COVID-19 em medicina intensiva. ICitado $2020 \mathrm{Mai}$ 30]. 2020. Disponivel em: https://www.amib.org.br/ fileadmin/user_upload/amib/2020/abril/04/Recomendacoes_AMIB04042020_10h19.pdf

20. Rio Grande do Sul. Secretaria Estadual da Saúde. Centro Estadual de Vigilância em Saúde. Laboratório Central de Saúde Pública (LACEN/RS). Investigação para coronavirus 2019 - ncov / influenza. Orientações para coleta e transporte de secreção respiratória. [Citado 2020 Jun 06]. 2020. Disponível em: https://atencaobasica.saude.rs.gov.br/upload/ arquivos/202002/04110353-2020-orientacoes-coleta-amostra-coronavirus-janeiro.pdf

21. Otto C, Schumacher B, Wiese LPDL, Ferro C, Rodrigues RA. Fatores de risco para o desenvolvimento de lesão por pressão em pacientes críticos. Enferm Foco. 2019; 10(1):7-11.

22. Conselho Federal de Enfermagem (COFEN). Resolução n 639, de 6 de maio de 2020. Dispõe sobre as competências do enfermeiro no cuidado aos pacientes em ventilação mecânica no ambiente extra e intra-hospitalar. [Citado: 2020 Jun 10] Diário Oficial da União. 2020;87:222. Disponivel em:pesquisa.in.gov.br/ imprensa/jsp/visualiza/index.jsp?data $=08 / 05 / 2020 \&-$ jornal $=515 \&$ pagina $=222$

23. Hall A. Administração de medicamentos. In: Potter PA, Perry AG, Stocker PA, Hall AM, editores. Fundamentos de enfermagem. $8^{a}$ ed. Rio de Janeiro: Elsevier. 2013. p. 583-685

24. Brasil. Agência Nacional de Vigilância Sanitária (ANVISA). Necessidade de reforço nas ações de prevenção de eventos adversos e infecções relacionadas à assistência à saúde durante a pandemia de covid-19. COMUNICADO GVIMS/GGTES/DIRE1/ANVISA N ${ }^{\circ}$ 01/2020. [Citado 2020 Jun 06]. 2020. Disponivel em: https://ameci.org.br/necessidade-de-reforco-nas-acoes-de-prevencao-de-eventos-adversos-e-infeccoes-relacionadas-a-assistencia-a-saude-durante-a-pandemia-de-covid-19/ 
25. Guimarães HP, Ujakow DCS, Rodrigues RR, Freitas APR, Correa TD et al. Associação Brasileira de Medicina de Emergência (ABRAMEDE). Associação de Medicina Intensiva Brasileira (AMIB). Recomendações para intubação orotraqueal em pacientes portadores de COVID-19. Versão N.3 /2020. Atualizada de 10/04/2020. [Citado 2020 Jun 10] Disponivel em: abramede.com.br/ wp-content/uploads/2020/04/Recomendacoes-1OT-FINAL-REVISAO-100420.pdf

http://abramede.com.br/wpcontent/uploads/2020/04/Recomendacoes-IOT-FINAL-REVISAO-100420.pdf.

26. World Health Organization. Clinical management of severe acute respiratory infection when novel coronavirus (2019-nCoV) infection is suspected: interim guidance, 28 January 2020. [Citado 2020 Jun 08]. Disponivel em: https://apps.who.int/iris/handle/10665/330893

27. Vollman K, Dickinson S, Powers J. Pronation Therapy. In: Wiegan DL, organizador. AACN procedure manual for high acuity, progressive, and critical care. $7^{\text {th }}$. Missouri:Elsevier; 2016. p.142-63

28. Van Doremalen N, Bushmaker T, Morris DH, Holbrook MG, Gamble A, Williamson BN, et al. Aerosol and surface stability of SARS-CoV-2 as compared with SARS-CoV-1. N Engl J Med. 2020;382(15):1564-7. https:// doi.org/10.1056/NEJMc2004973

29. Maben J, Bridges J. Covid-19: Supporting nurses' psychological and mental health. J Clin Nurs. 2020;00:19. https://doi.org/10.1111/jocn.15307

\section{CORRESPONDÊNCIA}

Evelize Maciel de Moraes

Hospital de Clínicas de Porto Alegre - Rua Ramiro Barcelos, 2350 - Santa Cecilia, Porto Alegre - RS, 90035-007. 